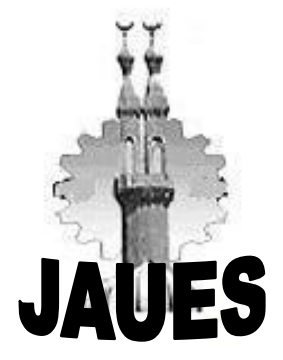

Journal Of Al Azhar University Engineering Sector

Vol. 11, No. 39, April 2016, 507-522

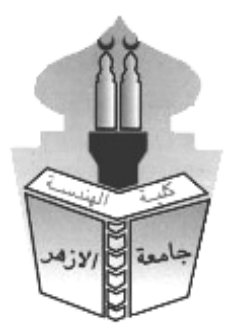

\title{
EXPERIMENTAL INVESTIGATION FOR MECHANICAL PROPERTIES OF FOAM BALLS LIGHTWEIGHT CONCRETE
}

\author{
Randa Fouad Ibrahim Fouad ${ }^{1}$, Amr zaher, Khaled Hilal ${ }^{2}$ and Aiman Ezzat ${ }^{2}$ \\ ${ }^{1}$ Civil Engineering Department, Canadian International College, Cairo, Egypt. \\ ${ }^{2}$ Structural Engineering Department, Ain Shams
}

\begin{abstract}
Researchers and industrialists' interest in foam balls lightweight concrete (FBLWC) to be used in structural applications is steadily increasing, since the increase in demand for structures are light in weight. FBLWC is currently believed to have a promising future. It was restricted to use as partition wall, thermal insulation and rehabilitation work in the past. In the last few decades with the understanding of the phenomenon underlying (FBLWC), efforts have been made to use it in structural application. A new kind of LWC was developed for foam balls lightweight concrete, in which conventionally aggregates is partially replaced by polystyrene foam particles, which combined the advantages of normal density concrete, cellular concrete and high workability [3]. The main objective of the research was to investigate and evaluate the mechanical properties of (FBLWC). The investigation focused on studying the compressive strength, tensile splitting strength, modulus of elasticity, stress-strain relationship in (compression and tension) and tension stiffening effect. The research work included an experimental and a numerical phase. The experimental program included the testing of (FBLWC) specimens under concentric axial load in both tension and compression to obtain the actual stress strain properties of the produced FBLWC. This study showed that the use of foam balls in lightweight concrete clearly reduced the density of the concrete from $24.00 \mathrm{kN} / \mathrm{m}^{3}$ to $18.45 \mathrm{kN} / \mathrm{m}^{3}$ which represented a reduction of $23 \%$. The average compressive strength for cube specimens was $27 \mathrm{MPa}$. And the average compressive strength for the cylinder specimens was 22.4 $\mathrm{MPa}$.
\end{abstract}

\section{INTRODUCTION:}

Foam balls lightweight concrete (FBLWC) has been a feature in the structural construction owing to its advantages over the normal weight concrete (NWC). According to (ACI 318R-14, 2014) structural, lightweight concrete is a concrete weighing substantially less than that is made of gravel or crushed stone aggregates. This definition is generally agreed to cover a broad spectrum of concretes ranging in (14.40 to 18.50$) \mathrm{kN} / \mathrm{m}^{3}$ and the cylinder compressive strength is more than 17.2 $\mathrm{MPa}$. Lower concrete density may be specified for non-structural applications. Many types of concrete fall within this range: some are cellular concretes made of foam or foaming agents, some are made of lightweight aggregates and some cellular concretes also contain lightweight aggregates. Lightweight foamed concrete is a kind of lightweight concrete which is lighter than normal concrete by mixing foam balls or foam agent into cement slurry.

\section{CONSTITUENT MATERIALS AND MIX PROPORTIONING:}

As a part of an ongoing research at the Faculty of Engineering of Ain Shams University, an innovative mix design was developed for foam balls lightweight concrete, in which conventionally used coarse aggregate is partially replaced by polystyrene foam particles. The materials used in this work were gravel, sand, Portland cement, water, foam balls and reinforcement steel bar. In addition to that, chemical admixtures of super plasticizer and silica fume are also used. The mixture consisted 
of Portland cement, coarse aggregates and sand in a proportion of 1:1.5:1.5 by weight, 0.3 was the water/cement ratio used for the mix. Table 1 summarizes the mortar batches. The designed cube compressive strength "f $\mathbf{f}_{\mathbf{c u}}$ " was $25 \mathrm{MPa}$.

Table 1: Concrete mixes' proportions/m3 and obtained properties

\begin{tabular}{cc}
\hline Concrete mix & Weight $\mathrm{kg} / \mathrm{m}^{3}$ \\
\hline Cement & 450 \\
Silica fume & 40 \\
Coarse Aggregate & 630 \\
Sand & 630 \\
Polystyrene Foam balls & 330 \\
Super Plasticizer & 13.5 \\
Water & 139 \\
\hline
\end{tabular}

\section{EXPERIMENTAL PROGRAM:}

\subsection{Geometry and description of tested specimens:}

Twenty seven specimens of cube, cylinder and prism of FBLWC were cast with the dimension, as shown in Table 2. The specimens were classified into four groups 1,2, 3 and 4. The specimen's dimensions and specified slenderness ratio satisfied the requirement of the (ISO 1920-3:2014) and (ECP 203-2007).

Group 1: Consisted of nine cube specimens coded C1, C2, C3, C4, C5, C6, C7, C8 and C9. The cubes had a side length of $150 \mathrm{~mm}$.

Group 2: Consisted of nine cylinder specimens coded CY1, CY2, CY3, CY4, CY5, CY6, CY7, CY8 and CY9. The cylinders had $150 \mathrm{~mm}$ diameter and $300 \mathrm{~mm}$ height.

Group 3: Consisted of nine prism specimens coded P-12-1, P-12-2, P-12-3, P-16-4, P-16-5, P-16-6, P-18-7, P-18-8 and P-18-9. The dimension is $150 \mathrm{~mm}$ length, $150 \mathrm{~mm}$ width and $300 \mathrm{~mm}$ height. The prism was reinforced with a single steel bar with diameter of 12,16 and $18 \mathrm{~mm}$. A strain gauge of $10 \mathrm{~mm}$ length was attached to each reinforcing bar.

In addition to bare steel bars of different diameters of $12 \mathrm{~mm}, 16 \mathrm{~mm}$ and $18 \mathrm{~mm}$ with a strain gauge in its middle. The length of tested specimens was $650 \mathrm{~mm}$.

For each FBLWC mix, three standard cubes of dimension 150x150x150 mm and cylinders of dimension $150 \times 300 \mathrm{~mm}$ were tested after 28 days to determine the compressive strength. Three cubes and five cylinders were tested after 28 days to draw the stress-strain relationship. One cylinder was tested to determine the Young's modulus. The last three cubes were tested to determine the tensile splitting strength. Each prism with different steel bar diameter was tested to obtain the tension stiffening effect on the behavior of FBLWC, as shown in Fig. 1.
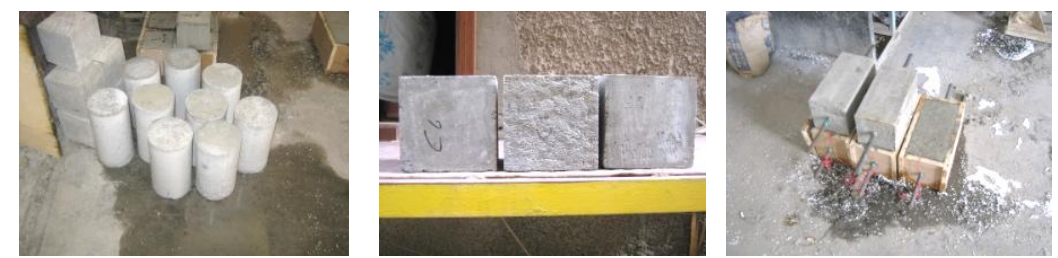

Fig. 1: cube, cylinder and prism specimens after being removed from the molds and curing 
Table 2: Specifications of the tested specimens

\begin{tabular}{|c|c|c|c|c|c|}
\hline Group No. & Specimens No. & Dimension (mm) & $\begin{array}{l}\text { Variable Under } \\
\text { Investigation }\end{array}$ & $\begin{array}{l}\text { Reinforcement } \\
\text { (Middle) }\end{array}$ & Batch \\
\hline \multirow{3}{*}{ G1 } & $\mathrm{C} 1, \mathrm{C} 2, \mathrm{C} 3$ & \multirow{3}{*}{$150 \times 150 \times 150$} & $\begin{array}{l}\text { Compressive } \\
\text { strength }\end{array}$ & ------ & \multirow{12}{*}{$\begin{array}{c}\text { FBLWC } \\
\mathrm{f}_{\mathrm{cu}}=25 \\
\mathrm{MPa}\end{array}$} \\
\hline & $\mathrm{C} 4, \mathrm{C} 5, \mathrm{C} 6$ & & Stress-strain curve & ------ & \\
\hline & $\mathrm{C} 7, \mathrm{C} 8, \mathrm{C} 9$ & & splitting test & ------ & \\
\hline \multirow{3}{*}{$\mathrm{G} 2$} & CY1, CY2, CY3 & \multirow[t]{2}{*}{ Diameter 150} & $\begin{array}{l}\text { Compressive } \\
\text { strength }\end{array}$ & ----- & \\
\hline & CY5 & & Young's Modulus & ------ & \\
\hline & $\begin{array}{c}\text { CY4, CY6, CY7, } \\
\text { CY8, CY9 }\end{array}$ & Height 300 & Stress-strain curve & ------ & \\
\hline \multirow{3}{*}{ G3 } & $\begin{array}{c}\mathrm{P}-12-1, \mathrm{P}-12-2 \\
\mathrm{P}-12-3\end{array}$ & & \multirow{3}{*}{$\begin{array}{l}\text { Tension stiffening } \\
\text { (Direct tension) }\end{array}$} & 1012 & \\
\hline & $\begin{array}{c}\text { P-16-4, P-16-5, } \\
\text { P-16-6 }\end{array}$ & $150 \times 150 \times 300$ & & 1016 & \\
\hline & P-18-9 & & & 1018 & \\
\hline \multirow{3}{*}{ G4 } & $\mathrm{S} 1, \mathrm{~S} 2$ & ( 12 & \multirow{3}{*}{ Tensile strength } & ------ & \\
\hline & S3, S4 & ( ) 16 & & ------ & \\
\hline & S5, S6 & ( 18 & & ------ & \\
\hline
\end{tabular}

\subsection{Test setup and loading scheme:}

The procedures used for testing the FBLWC specimens exposed to compression and tension load are described in the following sections. It is also contained details of the methods for basic mechanical properties such as compressive strength, density, modulus of elasticity, stress-strain behavior and tension stiffening effect.

\subsubsection{Unit weight (Density) of foam balls lightweight concrete:}

The test was performed using nine of $150 \times 300 \mathrm{~mm}$ cylinders and nine of 150x150x150 mm cubes. The specimens were removed from molds. And all specimens were weighed in the laboratory after 28 days. Density was the ratio of a substance's mass to its own volume.

\subsubsection{Compressive strength test of foam balls lightweight concrete:}

Compression tests (BS 12390-3:2009, ECP 203-2007 and ASTM C 39) were conducted to determine the compressive strength of concrete at the age of 28 days. In this test, a standard test load was applied parallelly between two plates to the longitudinal axis of a properly cured concrete cube or cylinder of a standard size, and then applying a force to the specimen by moving the crossheads together. The maximum load was obtained at the point which the cylinder and cubes ruptured. With this maximum load, the compressive strength can be easily calculated. The load interval was applied by $0.6 \pm 0.4 \mathrm{~N} / \mathrm{mm}^{2} / \mathrm{sec}$ rate. The equipment used in the test was a compression-testing machine matching the requirements of the standard specifications (ISO 1920-11:2014 part 4) or (BS 1881: part 115), as shown in Fig. 2.
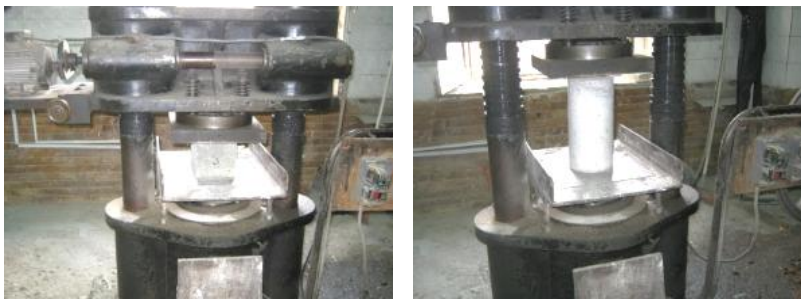

Fig. 2: Cylinder and cube specimens in the compression machine. 


\subsubsection{Modulus of elasticity test of foam balls lightweight concrete:}

The cylinders were fitted with a compressometer for determining the static modulus of elasticity according to (ISO 4012, ASTM C 469 and ECP 203-2007), as shown in Fig 3. The compressometer consisted of two yokes that formed a gauge distance of $165 \mathrm{~mm}$. The change in the length was determined from the reading of the dial gauge fitted between the two yokes. This Standard also states that the modulus of elasticity is applicable with the customary working stress range of 0 to $40 \%$ of the ultimate concrete strength (within or slightly beyond the linear range), as shown in Fig. 4. The load interval was applied by $0.6 \pm 0.4 \mathrm{~N} / \mathrm{mm}^{2} / \mathrm{sec}$.
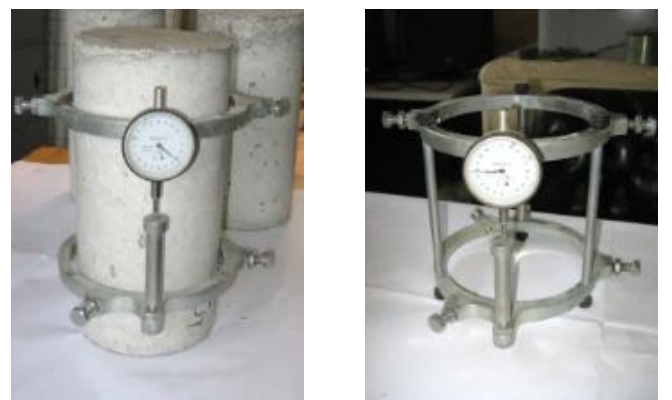

Fig. 3: The test cylinder fitted with the compressometer

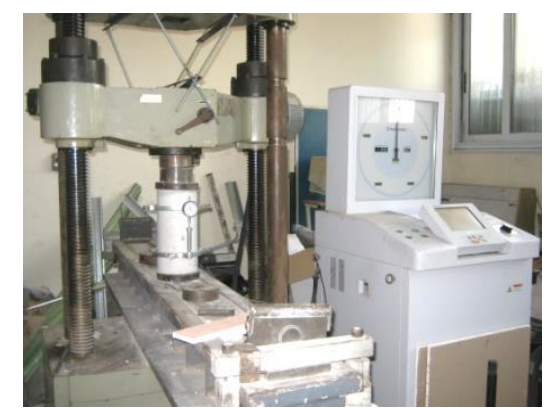

Fig. 4: Specimen's setup for E-modulus test

\subsubsection{Stress-strain relationship:}

The stress-strain relationship was determined for FBLWC using the cylindrical and cubic samples. The Universal testing machine (UTM) had a compressive capacity of $1000 \mathrm{kN}$ and was connected to a data acquisition system. The specimens were capped by using a poll seating to ensure full contact with the loading head, as shown in Fig 5. The loading rate was maintained at minimum rate 0.5 $\mathrm{mm} / \mathrm{minute}$. The stress-strain relationship was determined directly from the readings of the data acquisition system attached to the Universal testing machine. The cylindrical and cubic test specimens had two electrical strain gauges, fixed on the surface of the specimens using epoxy. (BS 1881 and ECP 203-2007))

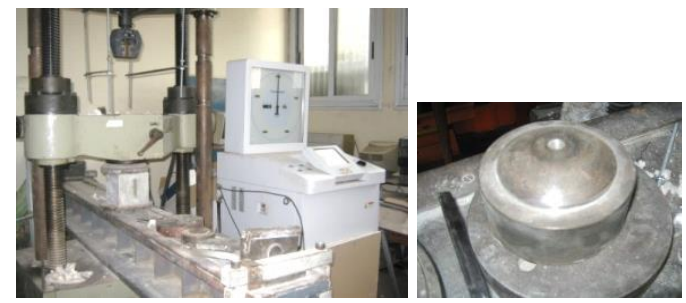

Fig. 5: (A): Test setup of cube specimens for the determination of the stress-strain relationship, (B) Poll seating

\subsubsection{Tensile splitting strength test:}

The tensile strength of FBLWC is also measured through the standard test of (ISO 4108 and ECP 203-2007)). This test refers to the split cube test, indirectly measures the tensile strength of concrete by compressing a cube through a line load applied along its length. This test can be performed in any concrete compression machine. It shall comply with the requirements of (BS-8110 Part 117). Supplementary steel loading plates are used to present the line load. It is a section of a cylinder, with a radius of $75 \mathrm{~mm}$ that the load is applied along a line on the surface of the specimen. Three similar samples of 150x150x150 mm were prepared for the test. The FBLWC specimen was placed on the UTM and supported longitudinally with steel loading plates carefully positioned along the top and bottom of the plane of loading of the specimen. The specimen was positioned centrally before the application of the load without shock at a rate of $0.5 \mathrm{~N} / \mathrm{mm}^{2} / \mathrm{s}$, as shown in Fig.6. 


\subsubsection{Tension stiffening:}

Fig. 6: Splitting tensile test on concrete cube specimens

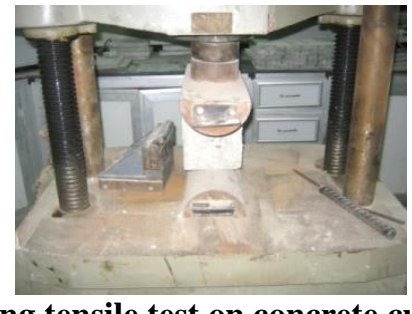

Tension stiffening tests had been carried out on prism specimens of 150x150x300 mm. One steel bar of 12,16 and $18 \mathrm{~mm}$ in diameter was used as the reinforcing bar in the middle. Specimens were loaded vertically through one-axial tension rod. At each load stage, the strains were measured by strain gauge, as shown in Fig.7.

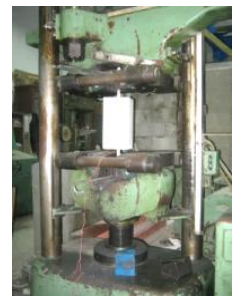

Fig. 7: Test setup for direct tension test.

\section{EXPERIMENTAL RESULTS AND DISCUSSIONS:}

\subsection{Density of hardened foam balls lightweight concrete:}

The density of FBLWC is one of parameters that affect the mechanical properties. The practical range of densities of foam balls lightweight concrete is between $(3.00-18.50) \mathrm{kN} / \mathrm{m}^{3}$. If the average density of the mix is above $19.00 \mathrm{kN} / \mathrm{m}^{3}$, the concrete can no longer be classified as structural lightweight, (ACI 318R-14, 2014). As shown in Table 3, using the foam balls in lightweight concrete clearly reduce the density of the concrete from $24.00 \mathrm{kN} / \mathrm{m}^{3}$ to $18.45 \mathrm{kN} / \mathrm{m}^{3}$ which represent a reduction of $23 \%$. The FBLWC density varies, within the batch as indicated by the standard deviation shown in Table 3.

Table 3: Density of FBLWC cubes and cylinders

\begin{tabular}{|c|c|c|c|c|c|c|}
\hline \multirow[b]{2}{*}{ Mix } & \multicolumn{3}{|c|}{$150 \mathrm{~mm}$ Cubes } & \multicolumn{3}{|c|}{ 150x300 mm Cylinders } \\
\hline & Specimens No. & $\begin{array}{l}\text { Weight } \\
(\mathrm{kg})\end{array}$ & $\begin{array}{l}\text { Density } \\
\left(\mathrm{kN} / \mathrm{m}^{3}\right)\end{array}$ & Specimens No & Weight (kg) & $\begin{array}{l}\text { Density } \\
\left(\mathrm{kN} / \mathrm{m}^{3}\right)\end{array}$ \\
\hline NWC & - & - & 24.00 & - & - & 24.00 \\
\hline \multirow{12}{*}{$\begin{array}{c}\text { FBLW } \\
\text { C }\end{array}$} & $\mathrm{C} 1$ & 6.49 & 19.23 & CY1 & 10.28 & 19.38 \\
\hline & $\mathrm{C} 2$ & 6.22 & 18.43 & CY2 & 10.90 & 20.55 \\
\hline & $\mathrm{C} 3$ & 6.14 & 18.19 & CY3 & 9.81 & 18.50 \\
\hline & $\mathrm{C} 4$ & 6.10 & 18.07 & CY4 & 9.70 & 18.29 \\
\hline & C5 & 5.90 & 17.48 & CY5 & 9.77 & 18.42 \\
\hline & C6 & 6.28 & 18.61 & CY6 & 10.31 & 19.44 \\
\hline & $\mathrm{C} 7$ & 6.40 & 18.96 & CY7 & 9.90 & 18.67 \\
\hline & $\mathrm{C} 8$ & 6.30 & 18.67 & CY8 & 10.10 & 19.04 \\
\hline & C9 & 6.20 & 18.37 & CY9 & 9.70 & 18.29 \\
\hline & Average & 6.22 & 18.45 & Average & 10.05 & 18.95 \\
\hline & Standard deviation $(\mathrm{kg})$ & & 0.175 & & & 0.395 \\
\hline & $\begin{array}{c}\text { Average standard } \\
\text { deviation } \%\end{array}$ & & & $28.5 \%$ & & \\
\hline
\end{tabular}

\subsection{Compressive strength:}

The most important mechanical property of used FBLWC is the compressive strength. After all, it is one of its prime attractions. The compressive strength after 28 days was determined by testing 150 mm cubes and 150x300 mm cylinders under compression load. Based on Table 4, it can be noticed 
that the compressive strength of FBLWC cubes with density (18.19-19.23) $\mathrm{kN} / \mathrm{m}^{3}$ ranges from (23.5-31.1) $\mathrm{MPa}$, while that of cylinders with density (18.50-20.56) $\mathrm{kN} / \mathrm{m}^{3}$ ranges from (20.3-23.7) $\mathrm{MPa}$. It can be noticed that cubes and cylinders have almost the same cube compressive strength of 27.0 $\mathrm{MPa}$. The ratio of the cylinder strength to the cube strength is 0.81 . Fig. 8 shows the relation between the FBLWC density $\left(\gamma_{\mathbf{c}}\right)$ and the cube compressive strength $\left(\mathbf{f}_{\mathbf{c u}}\right)$ of three cubes and three cylinders after using correction factor. That relation is best fitted as a linear relation, as given in Eq. (1).

$$
\mathbf{f}_{\mathrm{cu}}=2.4\left(\gamma_{\mathrm{c}}\right)-19
$$

Where:

$\mathbf{f}_{\mathbf{c u}}$ is cube compressive strength in $\mathrm{MPa}$

$\gamma_{c}$ is the density of specimen in $\mathrm{kN} / \mathrm{m}^{3}$

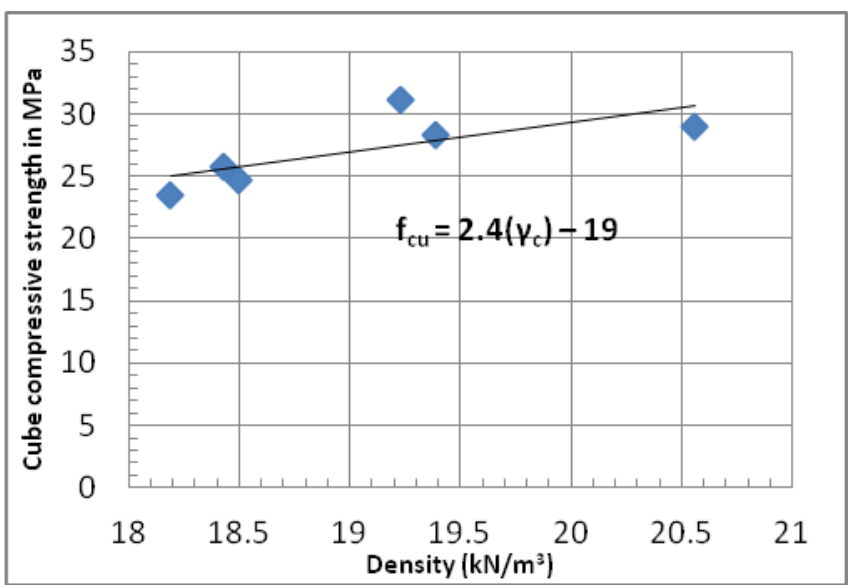

Fig. 8: Relationship between mix density and 28 day cube compressive strength

Table 4: Compressive strength results for FBLWC

\begin{tabular}{|c|c|c|c|c|c|c|c|}
\hline \multicolumn{4}{|c|}{150 mm Cubes } & \multicolumn{4}{|c|}{ 150x300 mm Cylinders } \\
\hline No & $\mathrm{P}_{\mathrm{f}}(\mathrm{kN})$ & $\mathrm{X}_{\mathrm{c}}\left(\mathrm{kN} / \mathrm{m}^{3}\right)$ & $\begin{array}{c}\mathrm{f}_{\mathrm{cu}} \\
(\mathrm{MPa})\end{array}$ & No & $\mathrm{p}_{\mathrm{f}}(\mathrm{kN})$ & $\mathrm{Y}_{\mathrm{c}}\left(\mathrm{kN} / \mathrm{m}^{3}\right)$ & $\begin{array}{c}\mathrm{f}_{\mathrm{c}}{ }^{\prime} \\
(\mathrm{MPa})\end{array}$ \\
\hline C1 & 700 & 19.23 & 31.1 & CY1 & 360 & 18.50 & 20.3 \\
\hline $\mathrm{C} 2$ & 580 & 18.43 & 25.7 & $\mathrm{CY} 2$ & 420 & 20.56 & 23.7 \\
\hline C3 & 530 & 18.19 & 23.5 & CY3 & 410 & 19.39 & 23.2 \\
\hline Average & 610 & 18.61 & 27.0 & Average & 390 & 19.48 & 22.4 \\
\hline
\end{tabular}

\subsection{Static modulus of elasticity:}

Modulus of elasticity is a necessary parameter to determine the stresses in materials and structures. The results of the static modulus for elasticity test are shown in Table 5 and Fig. 9. The strain results are calculated by dividing the average reading of dial gauges by the distance between the two yokes $(165 \mathrm{~mm})$. The stress is the applied load divided by the original cross-sectional area of FBLWC cylinder. The lightweight concrete usually has a modulus of elasticity of about half to three quarters (1/2-3/4) that of a normal weight concrete according to (ACI-318R-14, 2014).

Tested specimens are loaded under axial compression, the stresses and strains are calculated from recorded load and displacement values. The modulus of elasticity value is determined using two methods. The first method is the slope of the stress-strain curve as shown in Fig. 9. The second method is determined by calculating the stresses for interval load and the averages of dial gauges readings. The E-modulus is calculated by dividing the interval stress by interval strain. From the two methods the modulus of elasticity is $17385 \mathrm{MPa}$.

E1 $=$ Total stress $/$ Total strain $=7.92 / 0.00045=17461 \mathrm{MPa}$

E2 $=$ Interval stress $/$ Interval strain $=1.13 / 1.3 \times 10^{-4}=17385 \mathrm{MPa}$ 


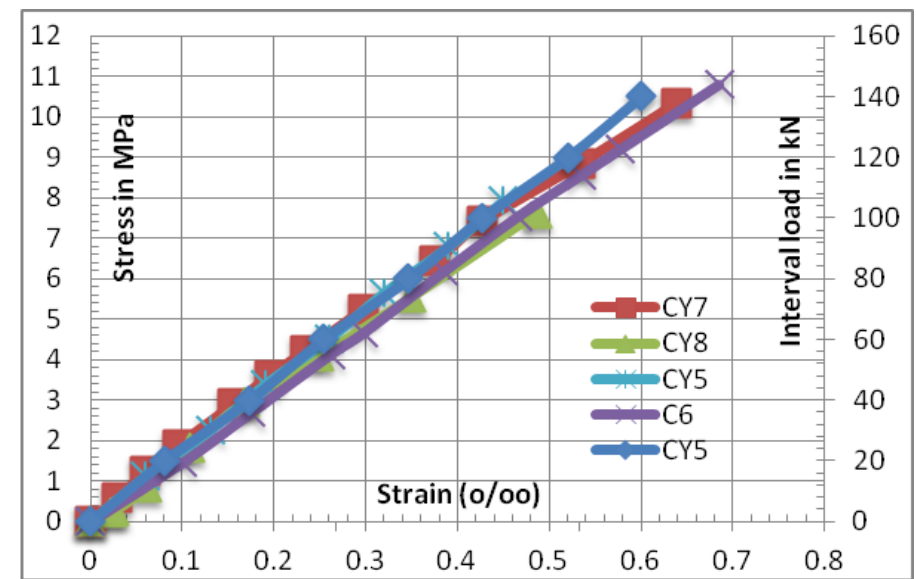

Fig. 9: The stress-strain curve from the dial gauges reading .

Table: 5 Applied load, gauges reading and corresponding calculated strain and stress values.

\begin{tabular}{|c|c|c|c|c|}
\hline \multicolumn{5}{|c|}{ 150x300 Cylinder } \\
\hline $\begin{array}{c}\text { Load } \\
(\mathrm{kN})\end{array}$ & $\begin{array}{l}\text { Dial gauge readingx } 10^{-3} \\
\mathrm{~mm}\end{array}$ & $\Delta$ Different & Stress (MPa) & Strain (o/oo) \\
\hline 20 & 35 & 19 & 1.13 & 0.06 \\
\hline 40 & 54 & 21 & 2.26 & 0.13 \\
\hline 60 & 75 & 24 & 3.39 & 0.19 \\
\hline 80 & 99 & 18 & 4.52 & 0.26 \\
\hline 100 & 17 & 21 & 5.65 & 0.32 \\
\hline 120 & 38 & 24 & 6.79 & 0.39 \\
\hline 140 & 62 & & 7.92 & 0.45 \\
\hline Interval load $=\mathbf{2 0}$ & & Average $=21.167$ & & \\
\hline $\begin{array}{c}\text { Interval stress }=1.13 \\
\mathrm{MPa}\end{array}$ & & Interval strain $=1.3 \times 10^{-4}$ & & \\
\hline
\end{tabular}

The relationship between the modulus of elasticity of concrete and its components' characteristics has been of deep interest for estimation properties of concrete. For normal strength concrete $\mathbf{f}_{\mathbf{c}}{ }^{\prime} \leq$ (40MPa), the modulus of the elasticity of concrete may be precisely expressed as a function of the compressive strength of concrete. It is the way that most national and international codes are using to express the modulus of elasticity of concrete. For instance, the (ACI- 318R-14, 2014) expresses the Young' s modulus as Eq. (2).

$$
E_{c}=0.033 W_{c}^{1.5}\left(f_{c}\right)^{0.5}
$$

Where $\boldsymbol{\gamma}_{\mathbf{c}}$ (the FBLWC unit weight in $\mathrm{kg} / \mathrm{m}^{3}$ ) is $1895 \mathrm{~kg} / \mathrm{m}^{3}$ and $\mathbf{f}_{\mathbf{c}}$ ' (cylinder compressive strength in $\mathrm{MPa}$ ) is $22.40 \mathrm{MPa}$, the modulus of elasticity from Eq. (2) is $16788 \mathrm{MPa}$. That shows good agreement between static modulus of elasticity obtained experimentally and that obtained from the ACI equation. The difference between the experimental value and analytics value is $3 \%$.

Most of the available data in the literature and (ACI-(318R-14,2014) on the modulus of elasticity considers that the ratio between the Young's modulus of $\mathbf{L W C}$ and $\mathbf{N W C}$ is about 0.5 to 0.75 . By using Eq. (2), the modulus of elasticity for normal weight concrete (the unit weight is $2400 \mathrm{~kg} / \mathrm{m}^{3}$ ) having same concrete strength is $23928 \mathrm{MPa}$. The ratio between the experimental modulus of elasticity of FBLWC and modulus of elasticity of NWC from (ACI- 318R-14, 2014) equation is 0.73 .

\subsection{Stress-strain curves:}

Concrete considered being strain-softening behavior, indicating a reduction in stress after the peak value with an increase in the deformation. Although the ductility of concrete is much lower than steel, it still exhibits significant deformation before fracture. The tests were carried out for two cylinders and one cubes. It has been noticed from experimental data from Fig. 10 that the maximum compression stress is $22.0 \mathrm{MPa}$ in cube specimen and 18.0 MPa in cylinder specimens. The average Young's modulus is $17235 \mathrm{MPa}$. 


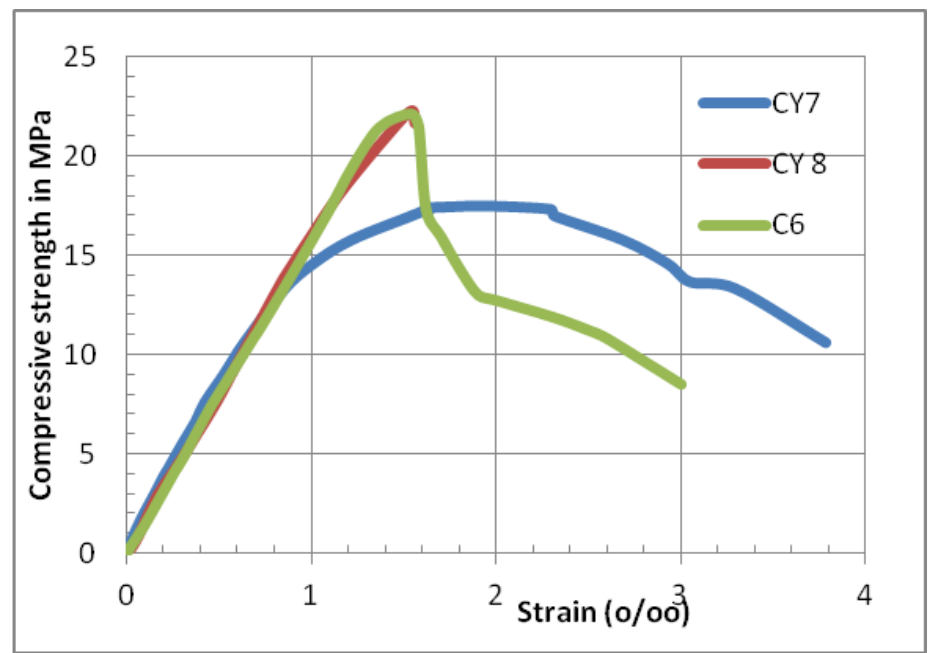

Fig. 10: The stress-strain curve for all specimens

The results, which are used to draw the stress-strain curve, are the averages of CY7, CY8 cylinder specimens and C6 cube specimen, as shown in Fig. 11. A correction factor of 0.81 (ratio of cylinder compressive strength to cube compressive strength) is used in order to modify the cylinder specimens results.

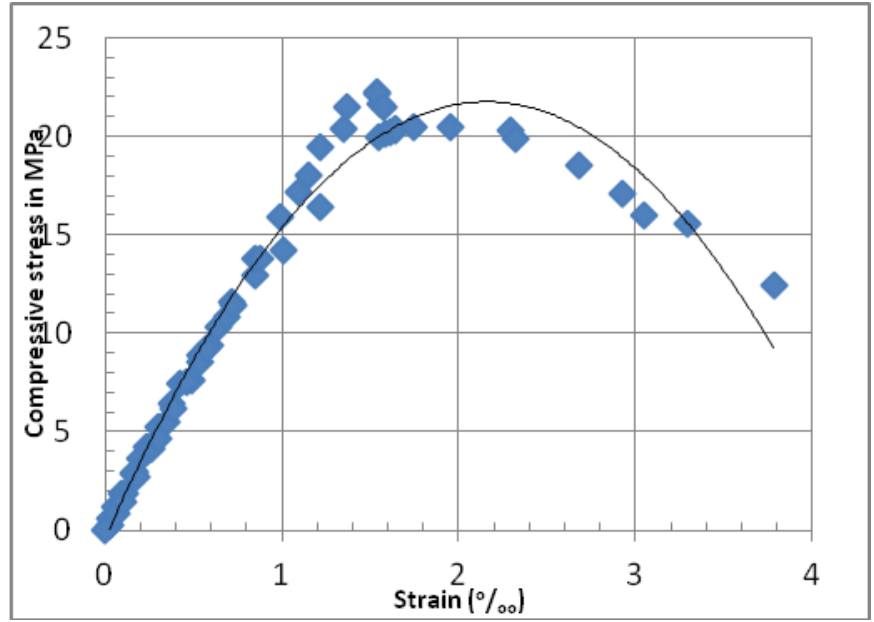

Fig.11: Average stress-strain curve of all specimens

Form Fig. 12, the obtained stress-strain curve has a linear elastic behavior up to $11 \mathrm{MPa}\left(40 \% \mathbf{f}_{\mathbf{c u}}\right)$. The peak strength is $22 \mathrm{MPa}\left(81 \% \mathbf{f}_{\mathbf{c u}}\right)$. The softening curve up to the crushing of concrete is at 12.60 $\mathrm{MPa}\left(47 \% \mathbf{f}_{\mathbf{c u}}\right)$. The maximum crushing strain $\boldsymbol{\varepsilon}_{\mathbf{u}}$ is 0.0035 and the strain at ultimate strength of concrete $\varepsilon_{0}$ is 0.0022 . The Young's modulus is $17235 \mathrm{MPa}$. Table 6 shows the obtained values of stresses and strains for FBLWC. The relation can be express by Eq. (3).

Where:

$$
f_{c}=-4.7\left(\varepsilon_{c}\right)^{2}+20.5\left(\varepsilon_{c}\right)-0.4
$$

$\mathbf{f}_{\mathbf{c}}$ is the FBLWC compressive stress in $\mathrm{MPa}$

$\boldsymbol{\varepsilon}_{\mathrm{c}}$ is the FBLWC strain in $(\%$ oo 


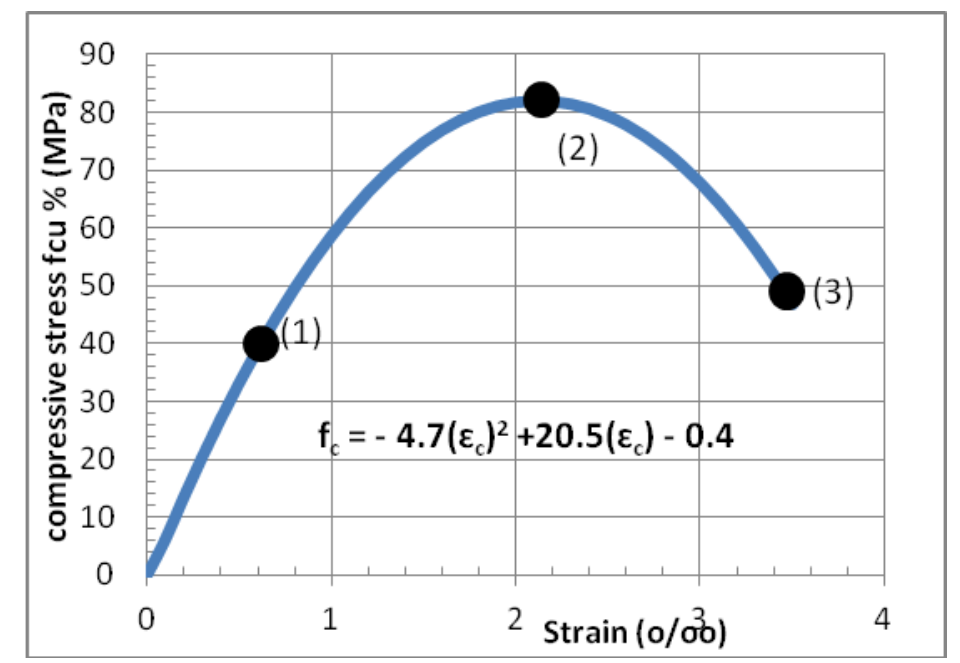

Fig. 12: The obtained stress-strain curve for foam balls lightweight concrete cube

Table 6. The key values of stress and strain for FBLWC cylinders and cubes

\begin{tabular}{|c|c|c|c|c|c|c|}
\hline \multicolumn{2}{|c|}{ (3): Failure point } & \multicolumn{2}{|c|}{ (2): Peak point } & \multicolumn{2}{|c|}{ (1): Yield point } & \multirow[b]{2}{*}{ Specimen type } \\
\hline Strain $(\%)$ & Stress (MPa) & $\begin{array}{l}\text { Strain } \\
(\%)\end{array}$ & Stress (MPa) & $\begin{array}{l}\text { Strain } \\
(\%)\end{array}$ & Stress (MPa) & \\
\hline 3.00 & 9 & 1.70 & 18 & 0.6 & 9 & Cylinder \\
\hline 3.50 & 12 & 2.20 & 22 & 0.7 & 11 & Cube \\
\hline
\end{tabular}

\subsubsection{The failure pattern of FBLWC cube and cylinder specimens:}

The failure mode of FBLWC cylinder and cube specimens observed during testing was similar to the normal weight concrete. The failure pattern of the FBLWC cube produced a ductile failure that was characterized by the dispersion of splitting inclined cracks over the volume of the cube. In fact, such failure seemed to indicate that the specimens failed from the outside to the inside, as shown in Fig.13. The intact core remained, which seemed to relate to the post-peak carrying capacity at least to some extent.
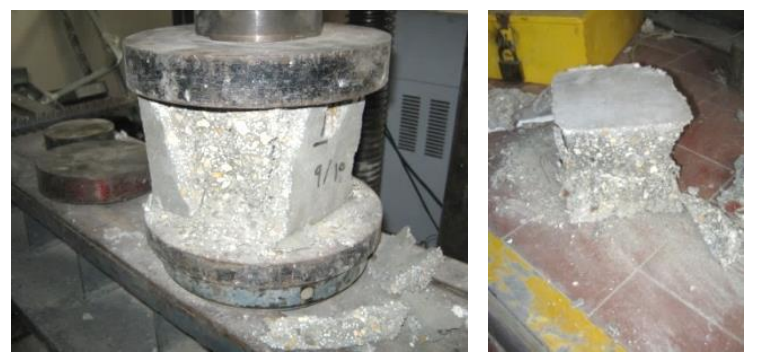

Fig.13: Failure stages during the UTM machine for C6

The failure pattern of cylinder specimens is shown in Fig. 14. The cylinders generally failed after reaching its peak load. They failed in axial splitting cracks parallel to the applied load and some yielding localized inclined cracks.
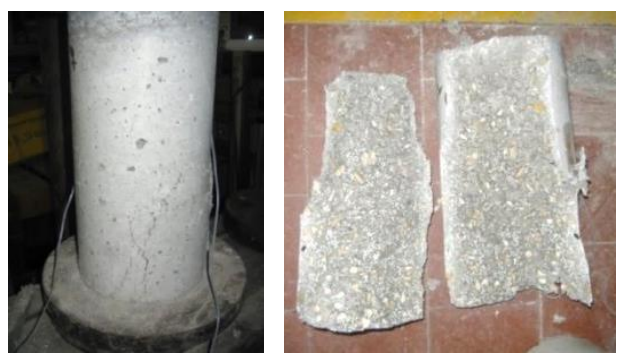

Fig. 14: Failure stages during the UTM machine for CY7 


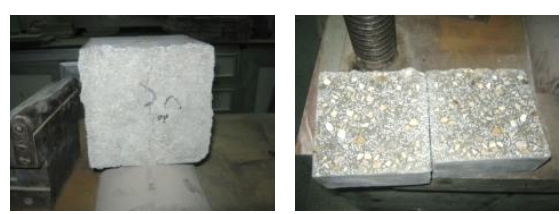

Fig. 15: Failure pattern of FBLWC cube specimens

\subsection{Tensile splitting strength and modulus of rupture:}

The structural properties of normal weight and lightweight concrete such as the shear resistance, bond strength and the resistance to cracking depend on the tensile strength. The higher the tensile strength is, the better the structural properties will be. The tensile strength obtained experimentally was the splitting tensile strength. Table 7 gives the value of splitting tensile strength of three 150x150x150 mm FBLWC cube specimens. The relation between the splitting tensile strength and the density is shown in Fig. 16. The corresponding compressive strength is calculated from Eq. (1) according to its density.

Table 7: The values of the splitting tensile strength of the FBLWC cubes

\begin{tabular}{ccccccc}
\hline Corresponding $\mathbf{f}_{\mathbf{c u}}(\mathbf{M P a})$ & Average $\mathbf{f}_{\mathbf{t}}(\mathbf{M P a})$ & $\mathbf{f}_{\mathbf{t}}(\mathbf{M P a})$ & $\begin{array}{r}\text { Density } \\
\mathbf{k g} / \mathbf{m}^{\mathbf{3}}\end{array}$ & $\begin{array}{c}\text { Tension load } \\
(\mathbf{k N})\end{array}$ & $\begin{array}{c}\text { Specimens } \\
\text { 27.0 }\end{array}$ \\
26.0 & 1.81 & 2.08 & 1896 & 73.8 & $\mathbf{C 7}$ \\
\hline 25.0 & & 1.77 & 1867 & 62.7 & $\mathbf{C 8}$ \\
\hline
\end{tabular}

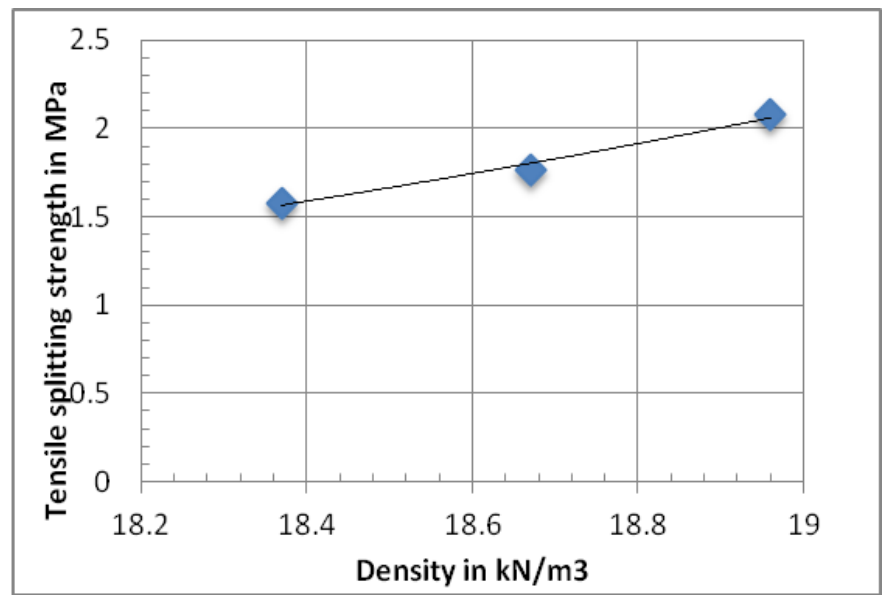

Fig. 16: Relationship between the splitting tensile strength and the density of the FBLWC

Fig. 17 shows the relationship between the splitting tensile strength and the corresponding compressive strength of the tested FBLWC cubes. The figure shows the relation between the splitting tensile strength and compressive strength. That relation is best fitted as a power relation. And it can be shown as Eq. (4):

$$
\mathbf{f}_{\mathrm{t}}=\mathbf{0 . 2 0}\left(\mathbf{f}_{\mathrm{cu}}\right)^{2 / 3}
$$

Where:

$\mathbf{f}_{\mathbf{t}}$ is the splitting tensile strength of FBLWC in MPa;

$\mathbf{f}_{\mathbf{c u}}$ is the compressive strength of FBLWC in MPa. 


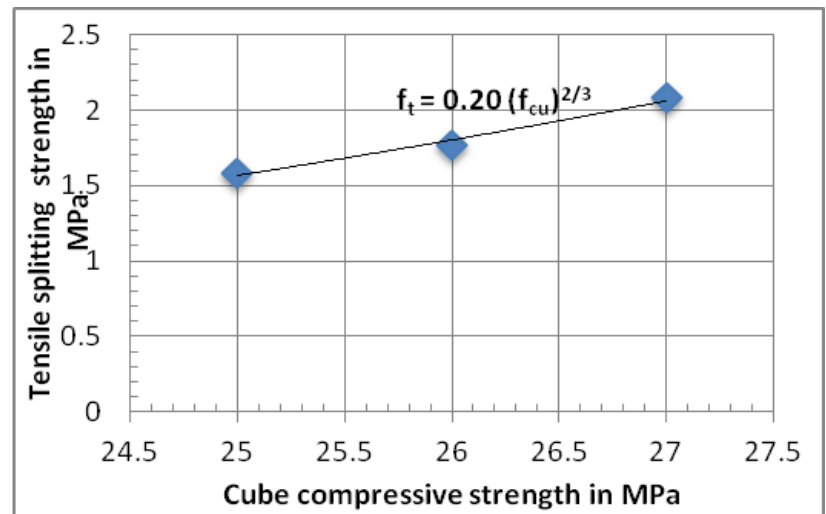

Fig. 17: Relationship between the splitting tensile strength and the cube compressive strength of FBLWC

Based on Fig. 17, the best regression line from this study is approximate to the empirical relation suggested by (ACI-318R-14, 2014). That relation has been modified from cylindrical specimens into cubic specimens and from psi to MPa.

$$
\mathbf{f}_{\mathbf{t}}=\mathbf{0 . 2 3}\left(\mathbf{f}_{\mathrm{cu}}\right)^{\mathbf{0 . 7}}
$$

The ratio between the splitting tensile strength and the cube compressive strength of the LWC specimens falls between 0.2 and 0.3 in terms of compressive strength for specimens proportional to (0.67-0.73) power of compressive strength [13] and [14], which conforms to the range suggested by ACI Eq.

(ACI-318R-14, 2014) presents the modulus of rupture for lightweight concrete by using modification factor $\lambda$ as a multiplier for NWC Eq. $\mathbf{0 . 6 2}\left(f_{c}^{\prime}\right){ }^{\mathbf{0 . 5}}$, where $\lambda=0.75$ for all-lightweight concrete. The calculated modulus of rupture for tested FBLWC is $2.20 \mathrm{MPa}$. Approximate relationships were found in the literature between the splitting tensile strength and the modulus of rupture for the lightweight concrete. The splitting tensile strength is generally lower than the modulus of rupture; ranging between (60-80)\% according to experimental data selected from available literature review [2], [8] and (ACI 318R-14, 2014). The ratio between splitting tensile strength obtained experimentally $(1.81 \mathrm{MPa})$ and calculated modulus of rupture $(2.20 \mathrm{MPa})$ for tested FBLWC is about $82 \%$.

\subsubsection{Failure pattern of FBLWC cube specimens:}

The failure of the foam balls lightweight concrete cube specimens by splitting tension is shown in Fig 15. The failure of the cube specimens resembles the classic splitting of the concrete into two halves by one splitting tensile crack.

\subsection{Tension stiffening of lightweight foamed concrete:}

Direct tension tests of nine prisms under axially tension load were conducted on 150 x $150 \mathrm{~mm}$ cross sections and $300 \mathrm{~mm}$ length specimens with 12,16 and $18 \mathrm{~mm}$ single diameter bar embedded centrally in the specimens, as shown in Table 2 and Fig. 8. 4.6.1. Failure pattern of FBLWC prisms:

For tested FBLWC prism, one can first observed the appearance of the initial transverse crack near the center of prism length. Then, under higher load, the splitting cracks phenomenon appeared and the concrete body was segmented into separate blocks for deformations at near yielding of the reinforcing. Longitudinal splitting cracks could be detected at the ends of specimen elements. This occurred for large deformations, usually beyond yielding of the steel reinforcing bar. This might be explained by the Poisson's effect and the high splitting pressure due to deformation of the reinforcing bar. At last, a secondary transverse network of cracks had grown from the splitting crack. The cracking pattern evolved when the steel failed, as shown in Fig. 18. 


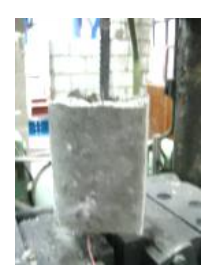

Fig. 18: Lateral cracks due to direct tension test for FBLWC

\subsubsection{Test results of bare bars:}

Fig. 19 presents the stress-strain curve for tested bare steel bar subjected to tensile force. Direct tension test was carried out for steel bar 12,16 and $18 \mathrm{~mm}$ in diameter.

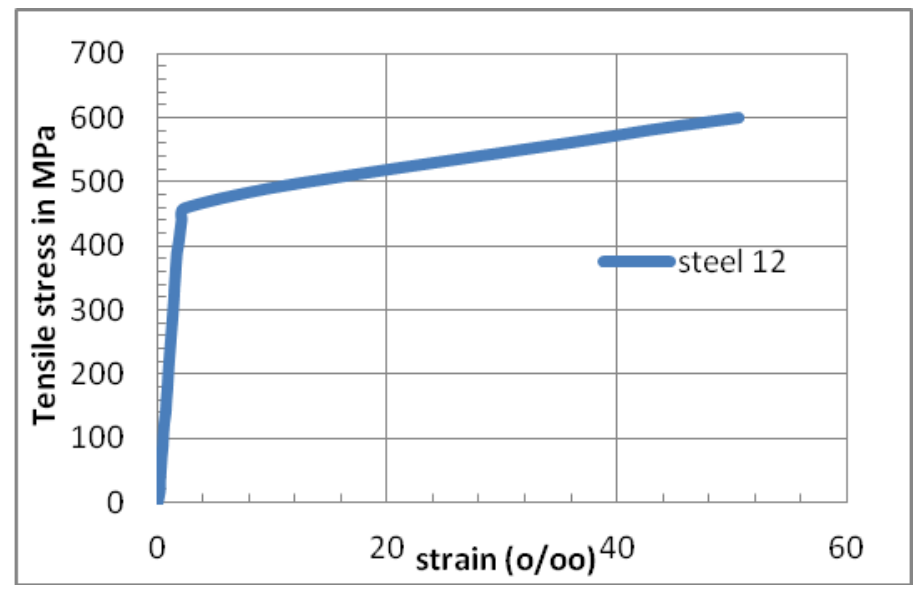

Fig. 19: Stress-strain curve for different steel bars

\subsubsection{Test results of embedded bars in FBLWC prisms:}

Fig. 20, Fig. 21 and Fig. 22 show the tensile stress-strain curves for a bar embedded in FBLWC which are subjected to direct tension. The corresponding curve of a bare bar tested is also plotted. The figures are the average of three tested specimens of each steel bar diameter. The difference between the two curves represents the contribution of the surrounding concrete in tension.

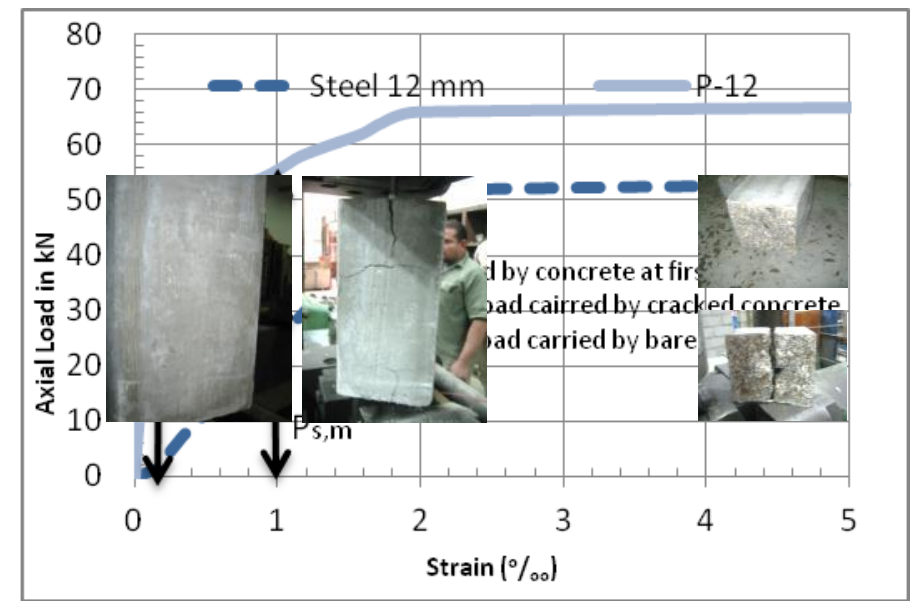

Fig. 20: Tensile stress-strain relationships for (P-12). 


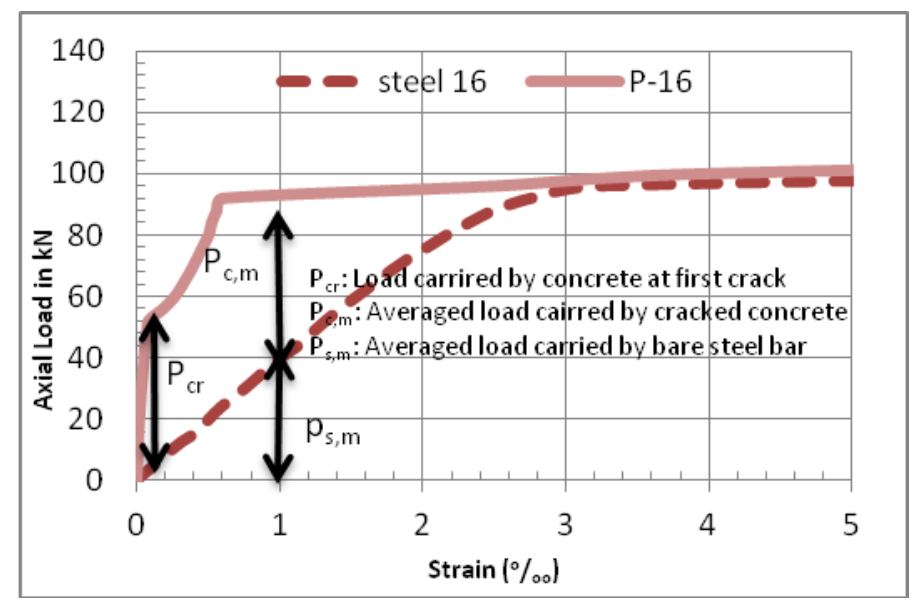

Fig. 21: Tensile stress-strain relationships for $(\mathbf{P}-16)$.

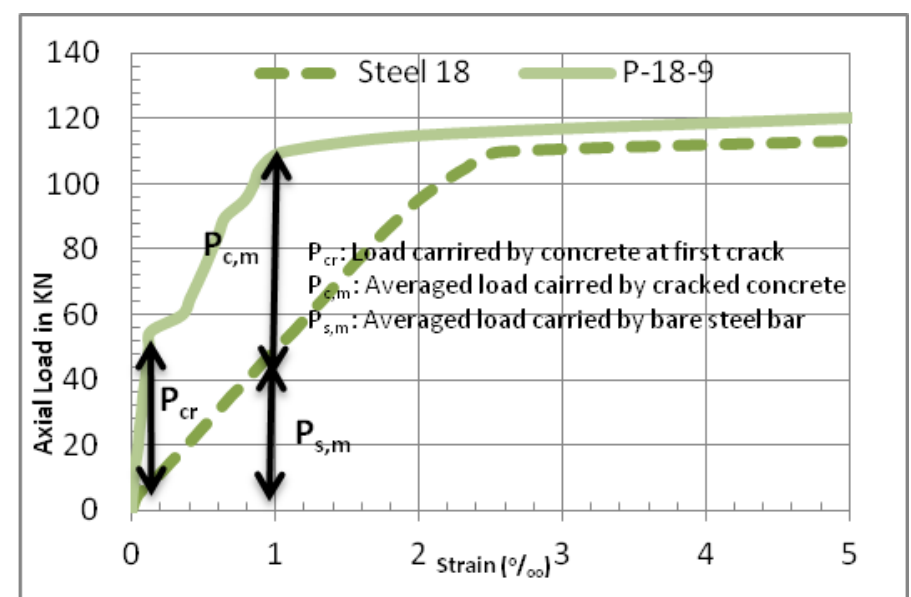

Fig. 22: Tensile stress-strain relationships (P-18-9).

4.6.4. Determination of actual tensile stress-strain curve of foam balls lightweight concrete:

The stress-strain relationship of FBLWC in tension contains two parts. The first part is the ascending part and it can be clearly observed that the tensile strength of concrete increases linearly with increasing strain up to cracking. The second one is the descending part. After cracking, the tensile strength decreases monotonically with increasing strain up to failure.

\subsubsection{Part 1: For the ascending part of tensile stress-strain curve "Tension-Stiffening"}

The prism is initially assumed to be uncracked and under a uniform strain corresponding to a total axial force $\mathbf{P}_{\mathbf{T}}$ causing a stress $\mathbf{f}_{\mathbf{t}}$ in the concrete and $\mathbf{f}_{\mathbf{s}}$ in the steel, as shown in Eq. (5). A uniform strain is considered to be under plane stress with area of concrete $\mathbf{A}_{\mathbf{c}}$ and area of steel $\mathbf{A}_{\mathbf{s}}$. As the load $\mathbf{P}$ increases, the stress in the concrete increases till the maximum tensile stress of the concrete reaches $f_{\text {cr }}$, where $f_{\text {cr }}$ is the stress causing the first cracking.

$$
\mathbf{P}_{\mathbf{T}}=\mathbf{f}_{\mathbf{t}} \cdot \mathbf{A}_{\mathbf{c}}+\mathbf{f}_{\mathbf{s}} \cdot \mathbf{A}_{\mathbf{s}}
$$

The cracking strength $\mathbf{f}_{\text {cr }}$ is determined by computing the stress on the specimen as in Eq. (6), as shown in Fig. 23 and Table 8.

$$
\mathbf{f}_{\mathrm{cr}}=\mathbf{P}_{\mathrm{cr}} /\left(\mathbf{A}_{\mathrm{c}}+\mathbf{n} . \mathbf{A s}\right)
$$

Where:

$\mathbf{f}_{\text {cr }}$ is average stresses at first crack;

$\mathbf{P}_{\mathbf{c r}}$ is average loads at first crack;

$\mathbf{A}_{\mathbf{c}}$ is concrete area of the member;

$\mathbf{A}_{\mathbf{s}}$ is the area of steel;

$\mathbf{n}$ is the modular ratio of elasticity $=\mathbf{E}_{\mathbf{s}} / \mathbf{E}_{\mathbf{c}}=200000 / 17385$ and is equal to 11.50 ;

$\mathbf{E}_{\mathbf{c}}$ is Young's modulus of concrete; 
$\mathbf{E}_{\mathrm{s}}$ is Young's modulus of steel.

To check the results, the following Eq. (7) has been used.

$$
\varepsilon_{\mathrm{cr}}=\frac{\mathbf{P}_{\mathrm{cr}}}{\mathrm{A}_{\mathrm{c}}+} / \mathbf{E}_{\mathrm{C}}
$$

Table 8: The stress and the strain at first crack.

\begin{tabular}{ccccc}
\hline Calculated $\varepsilon_{\text {cr }}\left(\%_{00}\right)$ & Strain $(\%)$ & Stresses $(\mathbf{M P a})$ & Crack load $\mathbf{P}_{\text {cr }}(\mathbf{k N})$ & Sample No. \\
\hline 0.10 & 0.12 & 1.59 & 38 & $\mathbf{P}-12$ \\
0.12 & 0.12 & 2.09 & 52 & $\mathbf{P}-16$ \\
0.12 & 0.13 & 2.12 & 54 & $\mathbf{P}-18$ \\
\hline
\end{tabular}

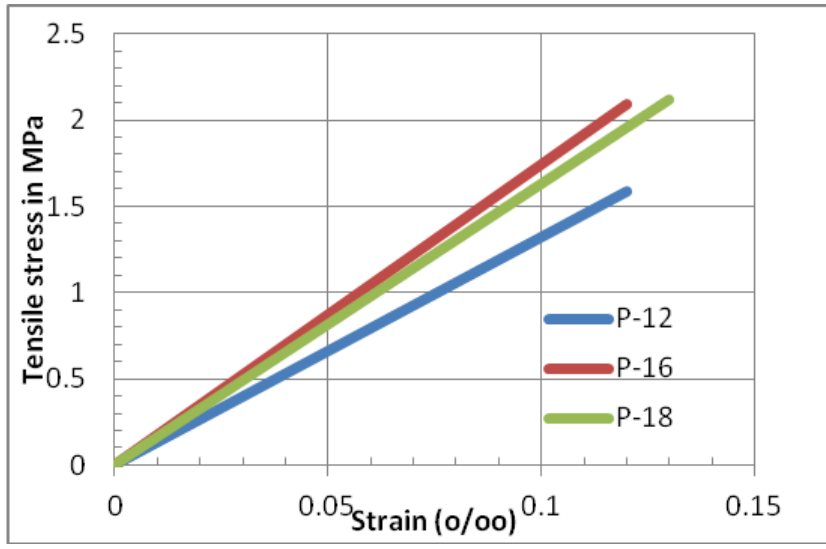

Fig. 23: Tensile stress-Strain relationship in concrete up to the first cracking.

\subsubsection{Part 2: For the descending part of the tensile stress-strain curve " Tension-softening":}

Tensile stress-strain curve has been evaluated in this study based on load sharing between steel bar surrounding by foam balls lightweight concrete. The shaded area in Fig. 24 represents the concrete contribution in the pre-cracking and the post-cracking ranges. At the given load $\mathbf{P}$ and the corresponding strain $\boldsymbol{\varepsilon}_{\mathbf{m}}$, the force carried by the concrete $\mathbf{P}_{\mathbf{c}, \mathbf{m}}$ can be determined from the test results as in Eq. (8):

$$
\mathbf{P}_{c, m}=\mathbf{P}-\mathbf{P}_{s, m}
$$

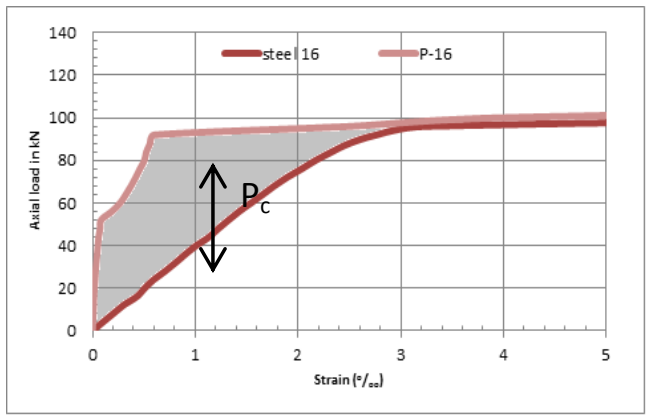

Fig. 24: Tensile stress-strain relationships for bare and embedded bar (P-16).

Tension stress is calculated by determining $\mathbf{P}_{\mathbf{c}, \mathbf{m},}, \mathbf{P}_{\mathbf{s}, \mathbf{m}}$ and $\mathbf{P}_{\mathbf{c r}}$, where $\mathbf{P}_{\mathbf{c}, \mathbf{m}}$ is average load carried by cracked concrete, $\mathbf{P}_{\mathbf{s}, \mathbf{m}}$ is average load carried by bare steel bar and $\mathbf{P}_{\mathbf{c r}}$ is load carried by concrete at first cracking, Dividing $\mathbf{P}_{\mathbf{c}, \mathbf{m}}$ forces by the effective area of concrete gives the average tensile stress carried by cracked concrete member $\left(\mathbf{f}_{\mathbf{t}}\right)$. The descending part of the specimens P-12, P-16 and P-18 which shown in Fig. 25, Fig 26 and Fig. 27 are plotted by the given equations.

$$
\mathbf{f}_{\mathrm{t}}=\mathbf{P}_{\mathbf{c}, \mathbf{m}} /\left(\mathbf{A}_{\mathbf{c}}+\mathbf{n} \cdot \mathbf{A}_{\mathbf{s}}\right)
$$

Where:

$\mathbf{f}_{\mathbf{t}}$ is average stresses at the cracked member;

$\mathbf{P}_{\mathbf{c}, \mathbf{m}}$ is average loads carried by the cracked concrete member;

$\mathbf{A}_{\mathbf{c}}$ is concrete area of the member; 
$\mathbf{A}_{\text {s }}$ is the area of steel;

$\mathbf{n}$ is the modular ratio of elasticity $=\mathbf{E}_{\mathbf{s}} / \mathbf{E}_{\mathbf{c}}=200000 / 17385$ and is equal to 11.50 ;

$\mathbf{E}_{\mathbf{c}}$ is Young's modulus of concrete;

$\mathbf{E}_{\mathbf{s}}$ is Young's modulus of steel.

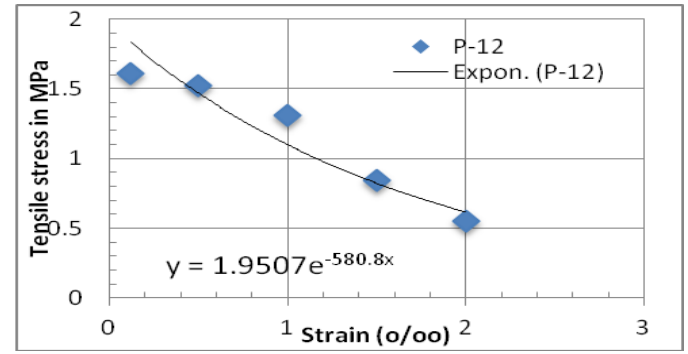

Fig. 25: The descending part for average of three specimens (P-12).

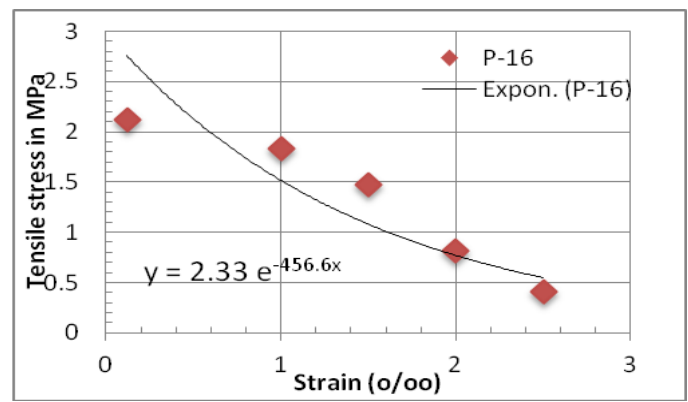

Fig. 26: The descending part for average of three specimens (P-16).

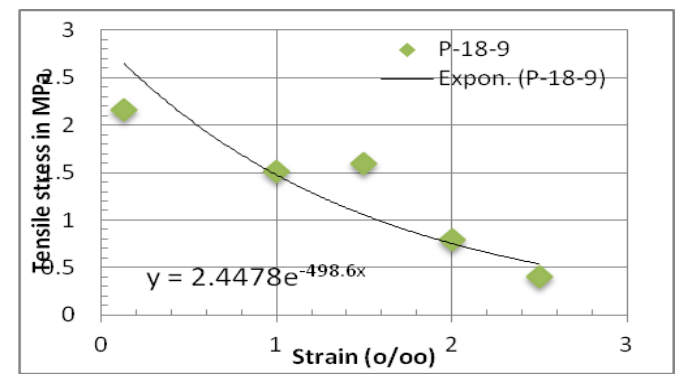

Fig. 27: The descending part for average of three specimens P-18-9.

By using equations (6), (8) and (9), the effective tensile stress is calculated for all the tested specimens with single steel bar in the middle of the prisms. All the results are shown in Fig. 28.

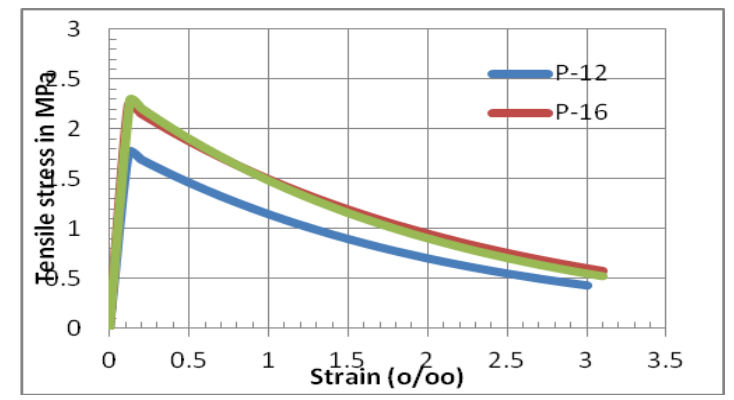

Fig. 28: Tensile stress-strain curves for P-12, P-16 and P-18.

The proposed stress-strain curve in Fig. 29 is the average of P-12, P-16 and P-18. The curve assumes a linear relationship up to the concrete cracking strength $\mathbf{f}_{\mathbf{c r}}$. The tensile strength of FBLWC is about (7-8) $\%$ of its cube compressive strength. After cracking, where the average strain $\varepsilon_{\mathbf{m}}$ exceeds the cracking strain $\varepsilon_{\text {cr }}$, the proposed stress-strain curve can be represented by the following exponential function, as the following Eq. (10).

$$
f_{t}=f_{c r} \cdot e^{456(\varepsilon c r-\varepsilon m)}
$$




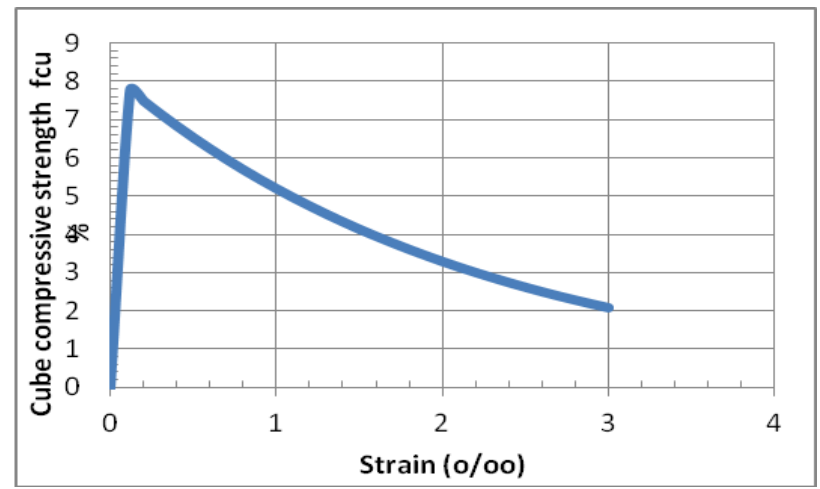

Fig. 29: Tensile stress-strain relationship of foam balls lightweight concrete prisms.

\section{CONCLUSION:}

A new kind of $\mathbf{L W C}$ was developed in the department of structural engineering of Ain Shams University. Through adding foam balls to the concrete mix, structural lightweight concrete was produced. By experimentally testing twenty seven cube, cylinder and prism specimens, the following characteristics were reached.

- The density of foam balls lightweight concrete is $18.45 \mathrm{kN} / \mathrm{m}^{3}$.

- The compressive strength of FBLWC cubes is $27 \mathrm{MPa}$, while the compressive strength of cylinders is $22.7 \mathrm{MPa}$.

$\bullet$ The Young's modulus of FBLWC is $17385 \mathrm{MPa}$. rupture is $2.20 \mathrm{MPa}$.

The splitting tensile strength of FBLWC is $1.81 \mathrm{MPa}$. The modulus of

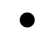
MPa.

The tensile strength of FBLWC from stress-strain curve in tension is 2.03

The design compressive strength of FBLWC from stress-strain curve in compression is $81 \%$ from its compressive strength. The design tensile strength of FBLWC from stress-strain curve in tension is ranging between (7-8)\% from its compressive strength.

\section{REFERENCES}

[1] ACI Committee 318, 2014, Building Code Requirements for Structural Concrete (ACI 318-14) and Commentary (ACI 318R-14), American Concrete Institute, Farmington Hills, MI, 430 pp.

[2] Akinkurolere, O.O., (2014), "A Comparative Analysis Of Modulus Of Rupture And Splitting Tensile Strength Of Recycled Aggregate Concrete", American Journal Of Engineering Research (AJER) E-ISSN: 2320-0847 P-ISSN

[3] A. Farghal Maree and K. Hilal Riad, (2014), "Analytical and experimental investigation for bond behaviour of newly developed polystyrene foam particles' lightweight concrete", Engineering Structures 58 (2014) 1-11.

[4] ASTM C 39. (2012), "Standard Test Method for Compressive Strength of Cylindrical Concrete Specimens", Annual Book of Standards Volume 04.02, ASTM International, West Conshohocken, PA.

[5] ASTM C 469. (2012), "Standard Test Method for Static Modulus of Elasticity and Poisson's Ratio of Concrete in Compression", ASTM International, West Conshohocken, PA.

[6] BS 8110-1: 2002, "British Standards Institution, Structural use of concrete-part 1: code of practices for design and construction". London: BS 882.

[7] ECP-203 (2007), "Design and Construction of Concrete Structures".

[8] Funso. F., Efe. I. \& Christopher. F., (2013), "A Study On The Compressive And Tensile Strength Of Foamed Concrete Containing Pulverized Bone As A Partial Replacement Of Cement", Pak. J. Engg. \& Appl. Sci. Vol. 13, July.

[9] ISO 1920-11:2014, International Organization for Standardization, Concrete-Strength of harden concrete, Part 4.

[13] Neville, A.M. and Brooks, J.J., (2010), "Concrete Technology", second edition, Prentice Hall, Pearson Education.

[14] Srinivasa P. R, Phani S.S, Sekhar. S., (2013), "Evaluation of Relationship Between Mechanical Properties of High Strength Self Compacting Concrete", American Journal of Engineering Research AJER) e-ISSN: 2320-0847 p-ISSN: 2320-0936 Volume-2, Issue-4, pp-6. 